\title{
Crisis de la educación como crisis de gobierno. Sobre la ejercitación del animal humano en tiempos neoliberales*
} \section{Artículos teóricos $\quad \begin{aligned} & \text { de Educación, N. }{ }^{\circ} 65 . \\ & \text { Segundo semestre de } 2013,\end{aligned}$ Bogotá, Colombia.}

//A crisis of education as a crisis of

goverment. On the exercise of the

human animal in neoliberal times

//Crise da educação como crise de

governo. Sobre a exercitação do animal

humano em tempos neoliberais

\footnotetext{
* $\quad$ Texto derivado de la investigación Noguera (2012). Fue presentado en el IV Coloquio Latinoamericano de Biopolítica y II Coloquio Internacional de Biopolítica y Educación, realizado en Bogotá del 2 al 5 de septiembre de 2013. Profesor asociado Universidad Pedagógica Nacional Bogotá, Colombia. Investigador Grupo Historia de la Práctica Pedagógica en Colombia. Doctor en Educación UFRGS-Brasil. Magíster en Historia UNC, Sede Bogotá. Correo electrónico: noeraernesto@gmail.com
}

\section{Resumen}

El propósito de este texto es presentar un conjunto de herramientas conceptuales que nos permitan comprender el complejo de transformaciones que estarían marcando la actual crisis de la educación. Parte este texto de una tesis: las prácticas educativas contemporáneas pueden ser entendidas como un síntoma de la crisis de las disciplinas (en el sentido de Foucault) y al mismo tiempo como una respuesta a esa crisis. A su vez, tales prácticas educativas pueden ser mejor comprendidas si las analizamos a la luz de la noción de gubernamentalidad neoliberal. Utilizando algunos conceptos de Nietzsche, Foucault y Sloterdijk y tomando como ejemplos dos personajes de ficción (Emilio de Rousseau y Bart de la serie televisiva Los Simpson), el autor problematiza tanto el borramiento del rol del adulto y de la educación como la aparición de la figura ambigua de un aprendiz permanente propia de las nuevas prácticas de gobernamiento de tipo neoliberal.

\section{Abstract}

The purpose of this paper is to present a set of conceptual tools that allow us to understand the set of transformations that would be determining the current crisis in education. This text starts from the thesis: contemporary educational practices can be understood as a symptom of the crisis of the disciplines (in the sense of Foucault) and at the same time as a response to that crisis. Also, such educational practices can be better understood if we analyze them in the light of the notion of neoliberal governmentality. Using concepts of Nietzsche, Foucault and Sloterdijk and taking as examples two fictional characters (Emilio by Rousseau and Bart from the TV series The Simpsons), the author examines both the erasure of the role of adult and education as the appearance of an ambiguous role of permanent learners belonging practices of neoliberal government.

\section{Resumo}

O presente texto apresenta um conjunto de ferramentas conceptuais para compreender as complexas transformações que marcam a atual crise da educação. O ponto de partida do texto e a seguinte tese: as práticas educativas

\section{Palabras Clave}

Crisis en la educación, crisis de gobierno, gubernamentalidad neoliberal, disciplina.

\section{Keywords}

Crise da educação, crise de governo, governamentalidade neoliberal, disciplina.

\section{Palavras chave}

Crise da educação, crise de governo, governamentalidade neoliberal, disciplina. 
contemporâneas podem ser entendidas como sintoma da crise das disciplinas (no sentido de Foucault) e ao mesmo tempo como uma resposta a essa crise. Por sua vez, tais práticas educativas podem ser melhor compreendidas se elas são analisadas à luz da noção de governamentalidade neoliberal. Utilizando conceitos de Nietzsche, Foucault e Sloterdijk e usando como exemplo duas personagens da ficção (Emilio de Rousseau e Bart da série de tv Os Simpsons), o autor problematiza tanto o apagamento do papel do adulto e da educação quanto o aparecimento da figura ambígua de um aprendiz permanente própria das novas práticas de governamento de tipo neoliberal.

Un malestar ronda el campo de la educación. En particular, lo percibimos y padecemos quienes trabajamos y convivimos con niños y jóvenes: sentimos que los saberes y las prácticas con que fuimos formados no pueden ser utilizadas para manejar nuestras relaciones con los nuevos (como diría Hanna Arendt). Las personas en la calle hablan de que los niños de hoy son más inteligentes que los de ayer y su relación con la tecnología los ha colocado en un lugar bien diferente al que tuvimos nosotros cuando éramos niños. Parece que los niños de hoy nacieron con un chip incorporado que los hace individuos más inteligentes, activos, autónomos, por lo menos en lo que se refiere a gran parte de sus elecciones cotidianas. Ese chip que les permite sintonizarse con las nuevas tecnologías les impide aproximarse a las antiguas: la tradicional cultura académica, soportada en los libros, aparece demasiado esquemática, lineal, densa y exige rigurosos procesos de ejercitación que deben avanzar lentamente a través de una serie tediosa de etapas. La versatilidad de los medios electrónicos, la disponibilidad de amplios volúmenes de información, la productiva industria del entretenimiento parecen conspirar contra el pensamiento y el conocimiento producto de largos procesos de persistente trabajo.

La típica infancia moderna, tal como la conocimos los adultos de hoy, parece haber desaparecido. Nos estamos acostumbrando a ver en nuestras aulas, en nuestras casas, no infantes, sino pequeños adultos, adultos en miniatura que no solo tienen derechos, sino que los exigen. Los pasivos y obedientes seres que fuimos cuando éramos niños son ya un asunto del pasado y queda claro que la actividad, o mejor, la hiperactividad es una marca de los nuevos, mientras que la obediencia, por ejemplo, es vista como signo de un pasado oscuro que ha quedado definitivamente atrás.

Estos son algunos de los elementos que permiten suponer la existencia de una crisis generalizada de la educación contemporánea. El propósito de este texto consiste en presentar 
un conjunto de herramientas conceptuales que nos permitan comprender el complejo de transformaciones que estarían marcando esa crisis. Parte este texto de una tesis: las prácticas educativas contemporáneas pueden ser entendidas como un síntoma de la crisis de las disciplinas (en el sentido de Foucault) y al mismo tiempo como una respuesta a esa crisis. A su vez, tales prácticas educativas pueden ser mejor comprendidas si las analizamos a la luz de la noción de gubernamentalidad neoliberal. Y aquí es preciso una aclaración: no es mi intención realizar un análisis teórico sobre las nociones foucaultianas, no se trata de un ejercicio hermenéutico sobre esas nociones. Mi propósito es construir unas herramientas que nos permitan pensar el núcleo de las problemáticas educativas y pedagógicas contemporáneas. En otro sentido, diría que, antes que utilizar a Foucault para pensar asuntos de la educación y la pedagogía, por el contrario, este ejercicio podría entenderse como la utilización de elaboraciones del campo de la educación y la pedagogía para pensar y operar sobre algunos problemas que Foucault dejó esbozados en sus últimos cursos.

Para entrar en materia, debo decir que el enfoque que sustenta esta exposición forma parte del trabajo de investigación que he venido desarrollando durante los últimos años y cuya tesis más general es la siguiente: lo que científicos sociales han Ilamado modernidad consiste, fundamentalmente, en aquel momento de la historia occidental en el que por primera vez se afirma la necesidad de enseñar todo a todos, según la proclama de Comenio, o, dicho en otras palabras, como el momento inédito en el que se inicia una intensa y extensa disciplinarización de la población (europea y americana) bajo la forma de una instrucción generalizada. Esto significa que es posible entender las prácticas pedagógicas como prácticas de gobierno, dirección o conducción de la población (de todos y cada uno) o como formas particulares de ejercitación, es decir, como diría Sloterdijk (2012, p. 17): "cualquier operación mediante la cual se obtiene o se mejora la cualificación del que actúa para la siguiente ejecución de la misma operación, independientemente de que se declare o no a ésta como un ejercicio".

Desde esa perspectiva, afirmo que la modernidad tiene una profunda marca pedagógica. No que haya tenido una causa educativa o que la educación haya sido su causa: la expansión de las disciplinas (en el doble sentido de saber y de poder), la explosión de los problemas de gobierno, la crisis de gobierno, el bloqueo del arte de gobernar durante los siglos XVI y XVII (Foucault, 2006), pero también el Ilamamiento intensivo a la elevación de la vida, el imperativo metanoético (conversión, transformación) dirigido a todos e impulsado por el Estado moderno y la escuela (Sloterdijk, 2012) fueron asuntos 
profundamente pedagógicos. No solo tuvieron implicaciones pedagógicas y educativas; además, constituyeron problemáticas pedagógicas y educativas que tuvieron consecuencias políticas, económicas y sociales.

Retomando la tesis inicial se podría decir, entonces, que lo que el profesor Foucault llamó en sus cursos gubernamentalidad neoliberal puede comprenderse de manera profunda si, tomando distancia de las doctrinas económicas, nos acercamos a los discursos y las prácticas educativas contemporáneas. Se trata, a la vez, de una precaución metodológica y de una apuesta teórica: precaución metodológica en la medida en que no debemos confundir gubernamentalidad neoliberal con doctrinas económicas neoliberales; apuesta teórica en la medida en que podemos comprender mejor la noción de gubernamentalidad si reconocemos que las prácticas pedagógicas son, fundamentalmente, prácticas de conducción de la conducta propia y de los otros y que desde el siglo XVI, por lo menos, esas prácticas han ocupado un lugar central en los procesos de gobierno de la población.

Hechas estas precisiones, podemos pasar a abordar directamente nuestro asunto central, es decir, que las prácticas educativas contemporáneas, entendidas como prácticas de gobierno de tipo neoliberal son, a la vez, síntoma y respuesta a la crisis de las disciplinas o, en términos más precisos, síntoma de y respuesta a la forma disciplinaria de ejercer el gobierno pedagógico de la población. Fue el propio Foucault (1978) quien utilizó la expresión de crisis de la disciplina en una conferencia en Kioto. Al respecto, decía:

La disciplina, que fue eficaz para mantener el poder, ha perdido una parte de su eficacia. En los países industrializados, las disciplinas entraron en crisis. Después de cuatro, cinco siglos, se consideraba que el desarrollo de la sociedad occidental dependía de la eficacia del poder para realizar su función. Por ejemplo, era importante dentro de la familia cómo la autoridad del padre o de los padres controlaba los comportamientos de los niños. Si este mecanismo se rompe, la sociedad colapsaría. Cómo el individuo obedecía era un asunto importante. Durante los últimos años la sociedad ha cambiado y los individuos también. Son cada vez más diversos, distintos e independientes. Hay cada vez más tipos de personas que no están más forzados a la disciplina, así que nos vemos 
obligados a pensar el desarrollo de una sociedad sin disciplina.

Ese mismo año, señalaba al periodista Duccio Trombadori que estaríamos en el comienzo de una enorme crisis, "de una reevaluación a gran escala del problema del gobierno" (Foucault, 2003) y comparaba esa situación con lo que aconteció durante los siglos $\mathrm{XV}$ y $\mathrm{XVI}$, periodo que, como sabemos por su curso Seguridad, territorio, población, fue el momento de la explosión del problema del gobierno, el momento de una crisis generalizada de gobierno expresada en acontecimientos como el protestantismo, la Contrarreforma, las revueltas campesinas, pero también momento en que aparece una novedosa preocupación por el gobierno (instrucción) de los niños, de los artesanos, de los pobres, de los indígenas americanos.

Esa crisis que Foucault percibe a finales de la década de 1970, esa crisis que apenas enuncia, que señala sin muchas pistas, ese fin de la era de las disciplinas, coincide con diagnósticos que hiciera Arendt entre finales de 1950 e inicios de la década de 1960 o con los que realizó Mead en 1969 en un ciclo de conferencias en Nueva York o con los de Hobsbawm cuando se refería a la revolución cultural del siglo XX. Desde la filosofía, la antropología y la historia, estos autores señalaban un hecho sin igual en la historia reciente: la radical transformación de las relaciones entre adultos y jóvenes. Arendt (2008) señalaba que la crisis de la educación que afectaba la sociedad norteamericana de su época tenía que ver con el carácter político de los Estados Unidos, que marcaba una fuerte tendencia a igualar o borrar las diferencias entre los jóvenes y los viejos, entre personas con talento y sin talento, entre niños y adultos, entre profesores y alumnos. Esa crisis de la educación que finalmente implicaba la crisis de la manera como los nuevos llegan al mundo y crecen en él, se encontraba asociada a una crisis de la autoridad y a un profundo cuestionamiento de la tradición, pues la incorporación de los nuevos, antaño tarea fundamental de los adultos, estaba ahora a cargo del propio mundo y sociedad infantiles.

Si el pasado no nos sirve como orientación para la educación de los nuevos, si, como consecuencia de ello, no sabemos cómo ni hacia dónde orientar, entonces la respuesta, frecuentemente, es condescendiente con la tendencia general hacia un dejar hacer y ser, y esta actitud, como diría Arendt, es un rechazo hacia la responsabilidad frente a los nuevos. En sus palabras:

Los niños no pueden desechar la autoridad educativa como si estuvieran en situación de oprimidos por una mayoría adulta, si bien hasta este absurdo de tratar a los niños como si fueran una minoría oprimida que necesita ser liberada se aplicó en las modernas 
prácticas educativas. Los adultos desecharon la autoridad y esto solo puede significar una cosa: que se niegan a asumir la responsabilidad del mundo al que han traído a sus hijos (Arendt, 1996, p. 202).

Por su parte, Margareth Mead (2006), a finales de la década de 1960, planteaba ya con claridad el conjunto de transformaciones que se estaba operando en la sociedad occidental (específicamente, en la sociedad norteamericana). Según esta antropóloga, la cultura contemporánea sería el momento de una transición que llevó de un tipo de organización cultural denominado posfigurativo, pasando luego por otro calificado como cofigurativo, para finalmente llegar a una condición que ella denomina como prefigurativa. Una cultura posfigurativa es aquella en la cual "el pasado de los adultos es el futuro de cada nueva generación" (p. 35) o aquella donde "los niños son educados de modo tal que la vida de sus padres y abuelos posfigura el curso de sus propias vidas" (p. 45). Esto significa que son los adultos y las tradiciones (saberes y prácticas) las que orientan, guían, conducen la vida de las nuevas generaciones; implica la hipótesis de que la forma de vida de la vieja generación es inmutable e incuestionable; implica, por eso, una valoración de la adultez, de la experiencia, del saber acumulado, de la tradición y de la obediencia, del sometimiento a las reglas.

Cuando, por efecto de las aceleradas o súbitas transformaciones culturales las nuevas generaciones se ven obligadas a aprender más de sus pares o de otros adultos que de sus padres y abuelos, es decir, cuando los saberes y vida de la generación vieja no son suficientes para adaptarse a las nuevas condiciones y se hace necesario aprender de los colegas, entonces nos encontramos frente a un tipo de cultura co-figurativa. En las propias palabras de Mead: "la cofiguración se produce en circunstancias en que la experiencia de la joven generación es radicalmente distinta de la de sus padres, abuelos y otros miembros más ancianos de la comunidad inmediata" (p. 69), y ello generalmente sucede como efecto de una catástrofe que diezma la población anciana, por efecto de una emigración hacia una nueva cultura, por un proceso de conquista o por una conversión religiosa, fenómenos todos ellos que llevan a hacer inoperante el saber de la tradición y el papel de los adultos y ancianos como guías para la vida de las nuevas generaciones.

Finalmente, en términos de Mead, estaríamos asistiendo a la constitución de una cultura prefigurativa, pues será el hijo, el 
recién llegado, el nuevo, y no el padre ni los abuelos, quien representará el porvenir: es el niño, el recién nacido quien hoy representa lo que será la vida, algo de lo que no sabemos, algo que ignoramos, pues los cambios acelerados, la velocidad de las transformaciones contemporáneas han hecho imposible vislumbrar cómo será el futuro. Se trata de un momento en el que la juventud ha llegado a ocupar el lugar protagónico que antaño ocupó el adulto. Decía al respecto Mead:

Antaño siempre había adultos que sabían más que cualquier joven en términos de experiencia adquirida al desarrollarse dentro de un sistema cultural. Ahora no los hay. No se trata solo de que los padres ya no son guías, sino de que no existen guías [...] No hay adultos que sepan lo que saben acerca del mundo en que nacieron quienes se han criado dentro de los últimos veinte años (p. 108).

Y recordemos que Mead estaba diciendo esto en 1969. El cambio acelerado, la innovación permanente como exigencia vuelven los viejos saberes, prácticas, normas, creencias y apuestas inciertos y a los adultos, inseguros. En su libro sobre La corrosión del carácter, Sennett (2010) muestra la impotencia de Rico (joven profesional de la nueva generación de empresarios de sí mismos) para orientar a sus hijos, pues bien sabe que la educación que le dio su padre (portero jubilado de una universidad) no funciona en las nuevas circunstancias, pero tampoco está seguro de que su vida nómade, competitiva y sujeta a permanentes cambios, tensiones, incertidumbres, pueda servir de modelo para ellos.

En este mismo sentido, Hobsbawm (1994) apuntaba en su Historia del siglo XX que la revolución cultural está asociada con el auge de una cultura específicamente juvenil muy potente que se desprendió de la tutela de los adultos: "con la excepción de China, donde el anciano Mao movilizó a las masas juveniles con resultados terribles, a los jóvenes radicales los dirigían en la medida en que aceptasen que alguien los dirigiera - miembros de su mismo grupo" (p. 326). La juventud pasó a ser un estrato social independiente y autónomo y pasó a considerarse ya no como una fase preparatoria para la vida adulta, sino como la fase culminante del pleno desarrollo humano (esto es particularmente visible en el caso de los deportistas de alto rendimiento).

Esa crisis de la educación, de la autoridad, esa revolución cultural, ese auge de la cultura juvenil, en fin, esa crisis de gobierno que Foucault anunciara después de su curso de 1978, podría ser interpretada como una crisis de la disciplina, es decir, como un síntoma del ocaso de los dispositivos disciplinarios $y$, a la vez, como una respuesta a esa misma crisis. Pero, para comprender 
esta afirmación, es preciso mirar con mayor detenimiento lo que significaría esa pérdida de eficacia para la disciplina a que se refería Foucault en la conferencia de Kioto. Siguiendo nuestra tesis de que la modernidad tiene una profunda marca pedagógica, intentaré mostrar en seguida cómo la educación moderna, surgida como concepto y como práctica desde el siglo XVII, se está abandonando en el mundo contemporáneo.

Decía, entonces, que el concepto moderno de educación es un concepto forjado en el siglo XVII y desarrollado, particularmente, con las elaboraciones de Kant y Rousseau, retomadas a comienzos del siglo XX por los llamados pedagogos activos. Entre su versión disciplinaria (Locke) y su formulación liberal (Rousseau), fue Kant quien por primera vez estableció la base conceptual para la educación al definirla como aquella acción constituida por los cuidados (con los niños) y la formación (o Bildung que, a su vez, está compuesta de la disciplina y la enseñanza). Para Kant, la educación implicaba la posibilidad de transformación de la animalidad en humanidad, lo que significaba la principal herramienta para la conformación del hombre, que nacía inacabado y frágil. La condición de la educación era, entonces, la existencia de un adulto y un infante o joven; se trata de una actividad jerarquizada donde uno dirige al otro con el propósito final de que ese otro consiga, como parte de esa dirección, su propia autonomía, es decir, alcance su propio autogobierno: gobernar, dirigir, conducir para que el otro aprenda a conducirse.

Por tal motivo, para Kant, la disciplina y la obediencia eran asuntos centrales de la educación; para él, era preferible la falta de instrucción que la falta de disciplina, pues la instrucción se puede adquirir en cualquier momento, mientras que la falta de disciplina (solo adquirida durante los años de la niñez) es imposible de alcanzar posteriormente. La disciplina es la condición para el control de la animalidad, para el gobierno de los instintos, de la salvajería; sin ella, el sujeto es presa de sus pasiones y nunca conseguirá que el propio entendimiento gobierne su vida.

En una perspectiva kantiana, y después de un balance de las definiciones de educación dadas por diferentes autores franceses, ingleses y alemanes, Compayré proponía en su Curso de pedagogía (1920) esta fórmula:

La educación es el conjunto de los actos reflexivos por medio de los cuales se ayuda a la naturaleza en el desarrollo de las facultades físicas, intelectuales y morales 
del hombre, para buscar su perfección, su felicidad y la realización de su destino social (p. 18).

Coincide con Rousseau en que tal educación debe estar en conformidad con las leyes de la naturaleza, pero considera que aquello que se llama naturaleza, en el fondo, es un ideal que cada pedagogo concibe a su manera y que, como señala el pensador inglés Alexander Bain, existen en la naturaleza humana instintos malos como la cólera, el odio, la antipatía, la envidia, entre otros. No se puede abandonar la naturaleza a sí misma y, por el contrario, es necesario establecer unas restricciones, como propone Kant. También, coincide con Rousseau en que la educación es producto de la libertad, pues el hombre no es un ser inerte y pasivo, sino libre $y$ activo, pero la actividad del alumno debe estar comprometida con su educación; por lo tanto, debe estar al servicio de la acción educativa del profesor, colaborar con él para llegar hasta donde se le conduce. De ahí que:

La educación no abandona la naturaleza a sí misma, sino que la vigila, le dicta sus reglas $y$, en caso de necesidad, la reprime. De un modo general, es obra de la autoridad al igual que la libertad, pues la autoridad adquirida por el maestro que sabe hacerse estimar y obedecer, le permitirá

acudir al convencimiento

con más frecuencia que a la represión. Cuanto más autoridad tenga, menos necesitará usarla (p. 24).

Pero no se debe olvidar que el fin último de la educación es el cultivo del carácter; por eso, no se debe temer a la libertad, sino encontrar en el propio alumno el freno necesario para reformar las pasiones y los malos instintos, es decir, buscar con la educación el establecimiento de mecanismos para que el propio sujeto se gobierne a sí mismo. En esta perspectiva, Compayré considera, en la vía de Herbart, que la disciplina tiene un fin superior, que es la formación del carácter, motivo por el cual resulta central para la educación. Así, antes que basarse en un conjunto de premios y castigos, debe ser preventiva, y eso solo es posible si el profesor sigue un método adecuado, una regularidad y continuidad de los ejercicios escolares, una utilización correcta del tiempo, una clasificación de los discípulos (no solo por su edad, sino por su grado de instrucción y desarrollo intelectual) y una vigilancia rigurosa. Pero aquí es preciso recordar que el fin de la disciplina es volverse inútil; aunque sea necesaria una sujeción, esta no impide la libertad: "que es la disciplina que nos imponemos a nosotros mismos, y el fin de la educación en todos los grados es hacer hombres libres" (p. 441). Citando a Gréard, concluye Compayré: 
[...] Substituir insensiblemente a las reglas que se le han dado las que él mismo se dé, a la disciplina de afuera aquella de adentro; liberarlo, no de un solo golpe al modo antiguo, sino día por día, rompiendo a cada progreso un eslabón de la cadena que ataba su razón a la razón del otro; enseñarle a salir de sí mismo, a juzgarse, a gobernarse como juzgaría y gobernaría a los otros; mostrarle, en fin, las ideas del deber público y privado que imponen a su condición humana y social: tales son los principios de la educación que de la disciplina escolar hace pasar al niño a la disciplina de su propia razón y crea, al ejercitarla, su personalidad moral (p. 442).

En una perspectiva similar a la de Compayré, pero con un matiz que introduce un elemento novedoso, Emile Durkheim llamaba la atención sobre el hecho de que los pedagogos modernos (entre ellos el propio Compayré) estuviesen de acuerdo, casi en su totalidad, en ver la educación como un asunto eminentemente individual. Por el contrario, decía: "considero como el postulado mismo de toda especulación pedagógica que la educación es un ente eminentemente social, tanto en sus orígenes como por sus funciones, y que, por tanto, la pedagogía depende de la sociología más estrechamente que de cualquier otra ciencia" (2003, p. 115).

Así como para las poblaciones fueron establecidos mecanismos biológicos para su reproducción, en el caso de las sociedades, la educación cumplió el mismo papel. Era la educación, y solo ella, la que podía garantizar la sobrevivencia de la sociedad. La educación fue ese mecanismo de reproducción de la sociedad en un doble sentido: de una parte, era la educación la que transformaba el ser "individual y antisocial que somos en el momento de nuestro nacimiento" (p. 83) en un ser apto para vivir en comunidad; por otra parte, era a través de la educación que los productos de una generación, en lugar de borrarse y desaparecer con su muerte, se acumulaban, se pasaban y se transformaban en la siguiente generación. La famosa definición de educación de Durkheim es ilustrativa en este sentido:

La educación es la acción ejercida por las generaciones adultas sobre aquellas que no han alcanzado aún el grado de madurez necesario para la vida social. Tiene por objeto suscitar y desarrollar en el niño un cierto número de estados físicos, intelectuales y morales que exigen de él tanto 
la sociedad política en su conjunto como el medio ambiente específico al que está especialmente destinado (p. 63).

Pero, a pesar de estas claridades introducidas por Durkheim, la perspectiva psicológica se impuso gracias a su íntima articulación con los desarrollos científicos de la biología. De esa manera, se constituyó a comienzos del siglo XX el movimiento de la Ilamada Pedagogía Activa o Escuela Nueva, movimiento más bien heterogéneo que agrupó diversas tendencias, pero que, finalmente, reforzaría el carácter individual de la educación y, más específicamente, concretaría o actualizaría las ideas que Rousseau había formulado más de medio siglo antes sobre la educación. Recordemos que, a diferencia de Kant, Rousseau no partía de la disciplina, ni pretendía enseñar nada, sin embargo, su idea de educación libre no significaba una renuncia a la dirección, o la conducción; se trataba de una nueva manera de hacerlo, una fórmula novedosa que consistía en establecer las condiciones para una autorregulación del individuo. Es a partir de la propia acción del sujeto en un medio particular que es posible educar. Recordemos que Emilio es sacado de la ciudad y colocado en el campo (medio natural) para que de esa forma, y a través de su actividad, inicie las experiencias diversas, cotidianas y naturales que le permitirán aprender las lecciones de la propia naturaleza, de las cosas y de los hombres. La libertad de Emilio no es una plena libertad, no es un dejar hacer, no es espontaneismo: se trata de una estrategia cuyo principio es gobernar más para gobernar menos, es decir, crear las condiciones para que la acción del individuo se convierta en un proceso de regulación de su conducta, de adaptación a las exigencias del medio y de satisfacción de sus impulsos naturales.

En este sentido, recordemos que el animal humano es, en términos de Nietzsche, el supremo producto de la cultura, es decir, del cultivo, de ese largo periodo prehistórico que llevó a hacer de una bestia un animal capaz de hacer promesas, un animal con una memoria de la voluntad (Nietzsche, 1984). La cultura como cultivo, como adiestramiento, como domesticación, es la actividad genérica del hombre, de tal forma que la única ley que no es arbitraria es, precisamente, la ley de obedecer a las leyes (Deleuze, 1986): la cultura consiste en crear hábitos al humano, hacerle obedecer leyes, en últimas, adiestrarlo. Nietzsche no duda de la importancia del adiestramiento ni de la ejercitación, a fin de cuentas el hombre no es más que un animal ascético; el problema es qué tipo de ejercitante se forma, qué tipo de asceta o de atleta o de acróbata se crea. Y esa es la cuestión central de la cultura y de la educación. Nietzsche nos recuerda que la cultura, el cultivo, el adiestramiento del hombre ha producido el bueno, bello y fuerte griego como el débil, enfermo y malogrado cristiano. 
¿Qué tipo humano se está formando hoy? Aquí volvemos nuevamente a nuestra tesis: la era del gobernamiento neoliberal es el síntoma y la respuesta a la crisis de una manera de formar humanos que podríamos calificar como la forma disciplinaria, el gobernamiento disciplinario, las antropotécnicas disciplinarias cuyo fundamento era la dirección o conducción de unos (adultos -maestros, padres) sobre otros (niños o jóvenes -estudiantes, hijos-) sobre la base de una cierta tradición (saberes, prácticas, técnicas) y una autoridad derivada del manejo de esa tradición y de la antecedencia en el mundo frente a los recién llegados.

Como soporte principal de la tesis que me he propuesto mostrar aquí, considero entonces que la crisis de la disciplina, la crisis contemporánea de gobierno, tiene que ver con la emergencia de una forma liberal del arte de gobernar, eso que Foucault llamaría gubernamentalidad liberal, pero, sobre todo, tiene que ver con la imposibilidad de su implementación o, en otras palabras, con los efectos que produjeron las tentativas de llevarla a cabo en distintos momentos y espacios sociales, principalmente desde comienzos del siglo XX. Así, si bien en el siglo XVIII se dan las condiciones para la aparición de un discurso que rechaza la conducción directa del individuo, la coerción y la ejercitación constante y vigilada como forma de llegar a una determinada manera de ser humano (las disciplinas) y que, por el contrario, sustenta que se debe dejar actuar la propia naturaleza, abandonar toda medida artificial de conducción para seguir a la naturaleza individual, permitir su crecimiento y despliegue en libertad, si bien todo eso aparece ya en el discurso de Rousseau, su despliegue social solo tendrá condiciones hacia el siglo XX, de manera restringida y en un medio que el propio Rousseau descartó, pues formaba parte de los productos de la civilización, pervertidora de la humanidad: me refiero a la escuela. Miremos entonces con detalle este proceso.

El naturalismo rousseauniano, su creencia en la bondad natural y en las potencias del ser humano se enmarca en una nueva forma de conducción de sí y de los otros que aspira a un gobierno suave, sin excesos, sin presiones externas directas: confianza plena en una naturaleza bondadosa que solo precisa de espacio, de tiempo y de libertad para desenvolver la humanidad primigenia marchitada por la civilización y su pretensiosa escuela (enseñanza). Pero esta propuesta de libertad y naturalidad no fue una renuncia al cultivo, al adiestramiento. Nada más extraño a ese gobierno que la idea de un dejar hacer o de un abandono silvestre. Se trata de una extraña forma de llevar a cabo el gobierno: invisibilizarlo o, 
mejor, trasladarlo del lado del adulto, del maestro hacia el medio, hacia la naturaleza. Eso lo entendieron muy bien los pedagogos de la escuela activa que pretendieron, antirrousseaunianamente, volver la escuela renovada el medio natural de la infancia.

El laissez-faire que percibimos en las prácticas educativas contemporáneas sería, entonces, un efecto imprevisto del liberalismo rousseauniano y, a la vez, una respuesta a la pérdida de eficacia de las disciplinas. El gobierno neoliberal sería la era de los sistemas autorreferenciales de Sloterdijk (2012) que funcionan para su propio beneficio dejando de ser funcionales en términos más amplios a la totalidad del sistema. La llamada contemporánea a la búsqueda de la felicidad y el éxito personal está en esta perspectiva. Igualmente sucede con la idea de pensar al humano como un aprendiz permanente, como un empresario de su capital humano cuyo éxito o fracaso solo depende de la calidad de sus elecciones y de sus habilidades para dejar fuera de juego a los competidores.

En ese sentido, podríamos decir que si Emilio -como personaje de ficción- fue el sueño de una humanidad mejor, una propuesta para la salvación de la humanidad, Bart Simpson -otro personaje de ficciónrepresenta hoy una forma de ser de la humanidad, pero antes que un horizonte de salvación o mejoramiento, se trata más bien de un espejo. Emilio fue un acontecimiento. Se trató de un nacimiento anticipado a su época, un ser intempestivo, un extemporáneo. Criticado por muchos y acogido entusiastamente por algunos, Emilio solo pudo ser celebrado plenamente cuando la psicología funcionalista, pragmatista y biologista de comienzos del siglo XX apropió la idea de la acción (agencia) individual como un asunto de adaptación. Entonces ahí Emilio cobró sentido, por cuanto eran los intereses y la acción autónoma del individuo, como parte de su naturaleza, aquello que debía constituirse en el fundamento de su educación. Pero en el momento de su nacimiento, no había ojos ni oídos para ver y entender lo que estaba emergiendo con la idea de una educación natural. El propio Rousseau habló de una educación negativa, pues no tenía muy claro aún cómo nombrar eso que se dibujaba con su pluma imaginativa y aventurera. Desde luego, $y$ a pesar de su paranoia, tampoco podría Rousseau haber imaginado que la criatura de su fantasiosa escritura devendría en una figura bien distinta, dos siglos después. Y es que Bart Simpson es un hijo de Emilio: por más esmerados que sean los padres, sus hijos pueden tomar caminos inimaginables: recordemos que no se puede educar en estricto sentido, tampoco gobernar, por fortuna.

Pero retomemos el hilo de nuestra historia. Decíamos que el nacimiento de Emilio fue un acontecimiento, pues emergió como una novedad en el discurso, en el pensamiento de su época. Rousseau propone varias ideas revolucionarias en su libro: Emilio no precisa ir a la escuela para 
educarse; Emilio no necesita ser enseñado para que pueda aprender; no es necesario enseñar a leer y escribir a Emilio desde muy temprana edad, es más, no debería leer, antes de la pubertad, más que un solo libro: Robinson Crusoe. Pero tal vez la más osada afirmación del libro sea que ¡Emilio no necesita de maestro! ¿Cómo sería, entonces, posible educar sin un maestro? Esa es justamente la novedad que propone Rousseau: educar sin maestro, sin enseñar, cosa que no quiere decir dejar a Emilio desamparado o libre de cualquier apoyo o guía adulto. En sentido estricto, diremos que lo que propone Rousseau en su libro es la educación de Emilio. Esa nueva educación, aquella que se dibuja en la pluma de Rousseau, es de otro tipo, es una educación en la libertad, pues la tendencia natural del niño es la perfectibilidad, el crecimiento, el desenvolvimiento que, a menos que sea estragada por la intervención artificial de la civilización, seguirá siempre una ruta hacia lo bueno, hacia el bien. Emilio no debería saber muchas cosas, su educación no estaba destinada al conocimiento de todas las cosas del mundo como garantía para su virtuosidad. Al final del recorrido en compañía de su ayo o conductor, Emilio no tiene una gran erudición, es más, su erudición (el conocimiento de las cosas del mundo) era bien menor que la de sus contemporáneos; sin embargo, su educación era superior. Emilio tiene todo lo que necesita para ingresar a la vida social y ser un ciudadano respetuoso y respetable: ha aprendido a ser un hombre (un ser humano), ha aprendido a obedecer a la naturaleza y la naturaleza es sabia y buena.

Para conocer ese arte de vivir, Emilio no necesitó de un maestro: Rousseau no fue el maestro de Emilio, él mismo se definió como su ayo, podríamos decir que como su pedagogo o su conductor, pues se trata de alguien que guía la conducta del otro: el propio Rousseau utiliza una palabra que literalmente se traduciría como gobernador (gouverneur) para definir la tarea de quien educa y que se diferencia de quien cría (nodriza) e de quien enseña o instruye (maestro o preceptor). Por eso Emilio puede ser educado sin un maestro y, por eso mismo, el Emilio es una obra subversiva: es subversiva por cuanto en su época de aparición, la forma que comenzaba a ser dominante era la escuela disciplinaria. Podríamos decir, incluso, que se trata de una propuesta libertadora o liberadora, siempre y cuando se tenga en cuenta que la libertad invocada por Rousseau es una "libertad bien regulada", como diría Tomás Tadeu (Silva, 1999).

Ahora bien, como Emilio, Bart Simpson ha llegado a ser una especie de ídolo porque encarna la forma de ser de la infancia 
contemporánea o, mejor aún, porque muestra esa quimera que ha llegado a ser eso que hoy llamamos infancia. Es claro para nosotros, adultos del siglo XXI, que Bart no es un típico infante, parece más bien una especie de adulto en miniatura (si lo comparamos con su padre Homero)... y aquí comienzan las dificultades, pues, a pesar de su apariencia, también resulta claro que Homero Simpson no es un adulto, pues se comporta más como un infante o un adolescente. La verdad, muchas de las figuras adultas de la serie no son propiamente adultas: los amigos de Homero, por ejemplo, se parecen más a adolescentes que a adultos, en el sentido moderno del término. El propio director de la escuela, el señor Skinner, resulta ser un personaje infantil en la medida que depende todavía de su madre quien, a su vez, lo considera y trata aún como un infante. Lo que tenemos, entonces, son una serie de figuras donde los roles aparecen difusos. Desde luego, existen figuras claramente modernas, es decir, definidas, como el caso de Marge, quien representa el adulto típicamente moderno, en su versión feminizada. Igualmente está Lisa, hermana de Bart, quien nos recuerda a la típica niña disciplinada y formada que se comporta racionalmente. El vecino, Ned Flanders, es otra imagen clara de un adulto moderno que educa a sus hijos según una estricta, pero dulce disciplina cristiana.

Bart, entonces, no es un típico niño moderno, es más bien esa quimera que con cuerpo de niño se comporta y piensa como un joven contemporáneo de clase media, es decir, quiere solo divertirse, pasarla bien, no le gustan los deberes $y_{1}$ desde luego, no quisiera ser adulto, no está en su horizonte, entre otras cosas, porque parte de sus referentes adultos solo son como adolescentes con cuerpos adultos, otras quimeras. En estas condiciones, se ve cómo ha sido posible la figura de Bart Simpson, o dicho en otras palabras, cómo ha sido posible la conformación de ese quimérico personaje. Si dejamos de lado a Marge, representante de la madre afectuosa moderna, observamos que Homero no es un padre, ni un adulto. Su relación con Bart es como una relación de pares: nunca se propuso educarlo, su hijo es como un compañero más de juegos. Esa actitud de Homero, inverosímil para la generación de adultos de la primera mitad del siglo XX, es efecto, en alguna medida, de las condiciones de su propia crianza. Homero fue uno de los primeros hijos de lo que Hobsbawm Ilama la revolución cultural del siglo XX, ese conjunto de transformaciones que afectó la estructura familiar y las relaciones entre los sexos y entre las generaciones. La madre de Homero fue una activista hippie que luchó contra las armas nucleares y tuvo que abandonar a su hijo y esposo para huir de la justicia. Por su parte, Abraham, su padre, es un irlandés, veterano de la Segunda Guerra Mundial que llegó a los Estados Unidos intentando reconstruir su vida. Después de la 
huida de su mujer, debió mantener solo a su hijo y no se caracterizó por ser un padre afectuoso ni atento, su relación fue más bien de frialdad.

Lo cierto es que Bart no tuvo como padre a un de adulto y que los otros adultos que lo rodean son también unas figuras ambivalentes o simplemente no puede aprender de ellos gran cosa. Y ese es el punto central de la conformación de Bart Simpson: como no había nada substancial que aprender de sus padres ni de los adultos que lo rodean, Bart tuvo que aprender por él mismo. No fue enseñado o, por lo menos, los intentos de educación y enseñanza de los adultos (entre ellos de Marge) fueron interceptados por la actitud negligente y relajada de Homero o por la rutinaria y desesperanzada actitud de sus maestros. Entonces, Bart tuvo que aprender: con sus pares de escuela (de unos, los durones o matones, que debía obedecer o soportar su voluntad, de otros, los nerdos o los débiles, que debía aprovecharse de ellos); tuvo que aprender con los adultos: que el mundo se parece a un parque de diversiones y a un gran centro comercial (shopping); tuvo que aprender con la tv: que no hay diferencia entre la realidad y la ficción, pues todo es ficción; tuvo que aprender con sus maestros: que no vale la pena ser adulto, pues llegarás a ser una amargado y un aburrido. En fin, Bart es el individuo de la era del aprendizaje permanente. Muy poco le es enseñado y si se le enseña algo, no le servirá de mucho en su mundo cambiante; su educación ha sido mínima. Todo lo que es se debe a que lo ha aprendido, pues vive en esa "sociedad del aprendizaje" que describiera Faure en su informe a la Unesco en 1973.

Un dispositivo de aprendizaje (Masschelein y Simons, 2013) está transformando la manera en que nos constituimos como sujetos, la manera en que nos conducimos y somos conducidos. Ya no estamos en la era de la enseñanza que dibujó Comenio, no pasamos por la educación como la soñó Rousseau y solo algunos han podido disfrutar de lo que un joven comunicador argentino Ilama la educación prohibida. Ahora estamos ante el mundo de Bart y sus amigos, el mundo de Homero, enfrentados al sueño de una especie de tierra del nunca jamás, una Neverland donde nadie quisiera crecer ni ser adulto y donde solo parece contar la diversión. Michael Jackson, con toda su fortuna de millones de dólares, es el mártir contemporáneo que murió intentando construir su propia Neverland. Pero la era del aprendizaje no es ese país de las maravillas en el que se empeñó en vivir Michael Jackson y en el que vive, como eterno infante, Bart Simpson; la era del aprendizaje 
es el sueño rousseauniano convertido en pesadilla, en términos menos coloquiales, es la crisis de la disciplina y a la vez, la crisis de la gubernamentalidad liberal que no consiguió operar pues, aunque quizás más eficaz, era mucho menos eficiente, pues exigía más gobierno; se trata del momento extremo en el que las prácticas liberales de conducción de la conducta se desprendieron de sus regulaciones (estatales o generacionales) y ahora solo dependen del propio individuo en cuanto agente, capital humano, empresario de sí mismo, aprendiz permanente, a lo largo de toda la vida. Digamos que esa sería la manera como el gobernamiento liberal consiguió hacerse eficiente: dejar al propio individuo, a los individuos, el problema de su regulación en un medio igualmente desregulado.

$\mathrm{Ni}$ enseñanza, ni educación, en sentido estrictamente moderno. Estamos, como Bart, entrando en un nuevo tipo de sociedad donde el gobierno de todos y cada uno tiene que ver con el aprendizaje permanente. $Y$, a diferencia de la enseñanza y de la educación, para aprender no necesitamos de otro más que como parte del medio o del ambiente que puede servir de acicate para nuestra propia acción de ejercitantes permanentes: para aprender no es necesario enseñar, ni educar, se trata de un comportamiento adaptativo cuyas bases innatas e instintivas, le permiten al organismo (individuo) conducir su conducta de manera eficiente en un medio determinado. La era del aprendizaje es el momento de la historia occidental en donde el individuo está obligado a comportarse como un agente de su propia conducta, como una individualidad que tiene intereses propios, particulares, potencias que explorar y explotar, habilidades que aprender o desarrollar, información que debe procesar o desechar, elecciones que tiene que tomar oportunamente si quiere llegar a ser exitoso y feliz, o por lo menos, feliz, pues en la era del posdeber (como diría Lipovetski) un cierto hedonismo no sólo se hace posible, sino deseable como gran ideal de vida.

Por todo ello, como pedagogos, como educadores, como maestros, como adultos, no podemos renunciar a educar y a enseñar, justamente por el futuro, por lo nuevo, por lo que vendrá, por eso mismo, entonces, educar, enseñar, formar es una manera de decir no al dispositivo de aprendizaje o, si se quiere, una contraconducta, por eso quizá sea el momento de tener el valor de decir, con Foucault, que "no queremos ser más gobernados de esa manera, con esos fines, por esos sujetos".

\section{Referencias bibliográficas}

Arendt, H. (1996). Entre el pasado y el futuro. Barcelona: Editorial Península.

Comenio, J. (1984). Didáctica magna. México: Editorial Porrúa.

Deleuze, G. (1986). Nietzsche y la filosofía. Barcelona: Editorial Anagrama. 
Foucault, M. (1978). La société disciplinaire en crise. Recuperado de http://1 libertaire.free.fr/MFoucault113.html

Foucault, M. (2003). El yo minimalista y otras conversaciones. Buenos Aires: Editorial La Marca.

Foucault, M. (2006). Seguridad, territorio, población. Buenos Aires: Fondo de Cultura Económica.

Foucault, M. (2007). Nacimiento de la biopolítica. Buenos Aires: Fondo de Cultura Económica.

Herbart, F. (2003). Pedagogia geral. Lisboa: Fundação Calouste Gulbenkian.

Hobsbawm, E. (1994). Historia del siglo XX. Barcelona: Editorial Península.

Kafka, F. (1995). La metamorfosis y otros ensayos. Barcelona: RBA Editores.

Locke, J. (1986). Pensamientos acerca de la educación. Madrid: Akal.

Mead. M. (2006). Cultura y compromiso. Estudio sobre la ruptura generacional. Barcelona: Gedisa.

Masschelein, J. y Simons, M. (2013). Se nos hace creer que se trata de nuestra libertad: notas sobre la ironía del dispositivo de aprendizaje. Pedagogía y Saberes, 39, 93-102.

Meirieu, P. y Develay, M. (2003). Emilio vuelve pronto... ise han vuelto locos! Cali: Nueva Biblioteca Pedagógica.

Nietzsche, F. (1984). La genealogía de la moral. Madrid: Alianza Editorial.

Noguera, C. (2012). El gobierno pedagógico. Del arte de educar a las tradiciones pedagógicas. Bogotá: Siglo del Hombre Editores/GHPP.

Rousseau, J. (1984). Emilio o de la educación. México: Editorial Porrúa.

Rousseau, J. (1999). Las confesiones. México: Conaculta-Oceano.

Sennett, R. (2010). La corrosión del carácter. Barcelona: Anagrama.

Silva, T. (1999). Liberdades reguladas. A pedagogia construtivista e outras formas de governo do eu. Petrópolis: Editora Vozes. Sloterdijk, P. (2012). Has de cambiar tu vida. Valencia: Pre-Textos. 